\title{
Analisis Keberlanjutan Pembangunan Kota Tepian Pantai (Studi Kasus: Kota Baubau Provinsi Sulawesi Tenggara)
}

\author{
Suparman Supardi ${ }^{1}$ \\ Politeknik Baubau, Baubau, Indonesia
}

Sigid Hariyadi

Departemen Manajemen Sumber Daya Perairan, Fakultas Perikanan dan IImu Kelautan Institut Pertanian Bogor, Bogor, Indonesia

\section{Achmad Fahrudin}

Departemen Manajemen Sumber Daya Perairan, Fakultas Perikanan dan IImu Kelautan Institut Pertanian Bogor, Bogor, Indonesia

Artikel Masuk : 3 September 2017

Artikel Diterima : 4 Oktober 2017

Tersedia Online : 29 Desember 2017

\begin{abstract}
Abstrak: Kompleksitas pembangunan di wilayah pesisir Kota Baubau perlu diantisipasi agar tidak mengganggu dan mengancam keberlanjutan ekosistem pesisir. Degradasi lingkungan akibat pembangunan dapat membawa bencana yang merugikan tidak hanya pada aspek ekonomi dan infrastruktur, tetapi juga jiwa manusia. Oleh karena itu, pembangunan yang dilakukan harus senantiasa mengacu pada prinsip-prinsip pembangunan berkelanjutan. Berdasarkan hal tersebut, maka perlu dilakukan analisis keberlanjutan guna mengetahui status keberlanjutan pembangunan Kota Baubau. Tujuan penelitian ini adalah untuk menganalisis keberlanjutan pembangunan Kota Baubau berdasarkan dimensi ekologi, ekonomi, sosial, infrastruktur dan teknologi, serta hukum dan kelembagaan. Data yang digunakan dalam penelitian ini meliputi data primer dan data sekunder yang diperoleh melalui studi literatur, diskusi pakar/pemangku kepentingan, wawancara, kuesioner, dan survei lapangan. Analisis keberlanjutan menggunakan beberapa teknik analisis yaitu multidimensional scaling, leverage, Pareto, dan Monte Carlo. Hasil penelitian menunjukkan Kota Baubau cukup berkelanjutan pada dimensi infrastruktur teknologi $(74,77)$ dan dimensi hukum kelembagaan $(65,87)$, namun kurang berkelanjutan pada dimensi ekologi $(32,90)$ dan dimensi ekonomi $(41,87)$, serta tidak berkelanjutan pada dimensi sosial $(20,61)$. Selain itu diketahui bahwa ada 35 atribut yang sensitif berpengaruh terhadap keberlanjutan pembangunan Kota Baubau.
\end{abstract}

Kata kunci: ekologi, ekonomi, hukum dan kelembagaan, infrastruktur dan teknologi, keberlanjutan, sosial

Abstract: The complexity of coastal development in Baubau City needs to be anticipated carefully for hindering coastal ecosystems sustainability away from disruptions and threats.

\footnotetext{
1 Korespondensi Penulis: Politeknik Baubau, Baubau, Indonesia

Email: suparmansupardi01@yahoo.com
} 
Environmental degradation resulted from developments could be disastrous to economic and infrastructure sectors as well as human lives. Therefore, development initiatives are supposed to comply with the principles of sustainable development. Accordingly, sustainability analysis is necessary to figure out the sustainability status of Baubau City development. The purpose of this study is to analyze the sustainability of Baubau City development in accordance with multidimensional measurement of ecological, economic, social, infrastructure and technology, and law and institution. The data used in this study include primary and secondary data obtained through literature studies, expert discussions/stakeholder, interviews, questionnaires, and field surveys. The sustainability analysis applies multidimensional scaling, leverage, Pareto, and Monte Carlo techniques. The results show that Baubau City is quite sustainable in technological infrastructure dimension (74,77), and institutional law dimension (65,87), but less sustainable in ecology dimension $(32,90)$ and economic dimension (41,87), and unsustainable in social dimension (20,61). In addition, there are 35 sensitive attributes affecting the sustainability of Baubau City development.

Keywords: ecology, economy, law and institution, infrastructure and technology, sustainability, social

\section{Pendahuluan}

Wilayah pesisir merupakan wilayah yang sangat produktif dengan berbagai ekosistem di dalamnya. Wilayah pesisir dan pulau-pulau kecil sudah sejak lama dimanfaatkan untuk beragam kegiatan pembangunan, sehingga menyebabkan wilayah pesisir rentan terkena dampak pembangunan. Seiring pertumbuhan penduduk yang begitu cepat, keberadaan wilayah pesisir kian dipadati permukiman dengan berbagai aktivitas pembangunan yang seringkali tumpang tindih dalam pemanfaatannya, sehingga pada akhirnya menimbulkan permasalahan sosial dan lingkungan hidup.

Kota Baubau memiliki luas wilayah $365,96 \mathrm{~km}^{2}$ yang terdiri dari luas daratan 293.18 $\mathrm{km}^{2}$ dan wilayah pengelolaan laut $72,78 \mathrm{~km}^{2}$, serta panjang garis pantai $\pm 55,92 \mathrm{~km}$ (BAPPEDA Kota Baubau, 2015; DKP Kota Baubau, 2014). Jumlah penduduk Kota Baubau adalah 154,8 ribu jiwa (BPS Kota Baubau, 2016). Kota Baubau menghadapi tantangan dalam kaitannya dengan kompleksitas kegiatan di wilayah pesisir dan pulau kecilnya, sehingga pemanfaatannya perlu lebih hati-hati dan terarah. Hal ini perlu dilakukan guna menunjang visi pembangunan pesisir Kota Baubau yang ingin menjadikan wilayah pesisir, laut dan pulau-pulau kecil sebagai kawasan prioritas dan strategis untuk pengembangan kota yang nyaman, maju, sejahtera, berbudaya dan berwawasan lingkungan.

Pemanfaatan wilayah pesisir Kota Baubau sebagai pusat aktivitas masyarakat dan pertumbuhan ekonomi dapat menyebabkan lingkungan kehilangan fungsi alamiahnya. Pembangunan wilayah pesisir yang umum dilakukan di Kota Baubau adalah dengan melakukan penimbunan atau reklamasi. Ini terbukti dengan bertambahnya luas daratan Kota Baubau yang sebelumnya hanya $221 \mathrm{~km}^{2}$. La Sara (2014) menyatakan bahwa penimbunan (reklamasi) pada daerah pasang surut menyebabkan fungsi ekologis (biologi dan fisik), kimia, sosial dan ekonomi wilayah pesisir hilang. Oleh karena itu, pembangunan yang dilakukan harus senantiasa mengacu pada konsep pembangunan berkelanjutan. Effendi (2009) menyatakan bahwa pembangunan pesisir yang optimal dan berkelanjutan dapat dicapai dengan upaya pemanfaatan ruang dan sumberdaya pesisir sedemikian rupa tanpa melebihi daya dukung (carrying capacity) kawasan untuk menyediakannya.

Berdasarkan pemaparan tersebut, maka dalam penelitian ini dapat dirumuskan tujuan penelitian, yaitu: 1) menganalisis status keberlanjutan pembangunan Kota Baubau meliputi dimensi ekologi, ekonomi, sosial, infrastruktur dan teknologi, hukum dan kelembagaan; 2) mengidentifikasi dan menjelaskan atribut sensitif yang berpengaruh terhadap keberlanjutan ekologi, ekonomi, sosial, infrastruktur dan teknologi, serta hukum dan kelembagaan di Kota Baubau. 


\section{Metode Penelitian}

\section{Lokasi Penelitian}

Wilayah administratif Kota Baubau meliputi delapan kecamatan yang terbagi atas enam kecamatan pesisir dan dua kecamatan bukan pesisir. Kecamatan pesisir meliputi Kecamatan Wolio, Kecamatan Betoambari, Kecamatan Batupoaro, Kecamatan Kokalukuna, Kecamatan Lea Lea, dan Kecamatan Bungi; sedangkan kecamatan bukan pesisir meliputi Kecamatan Murhum dan Kecamatan Sorawolio.

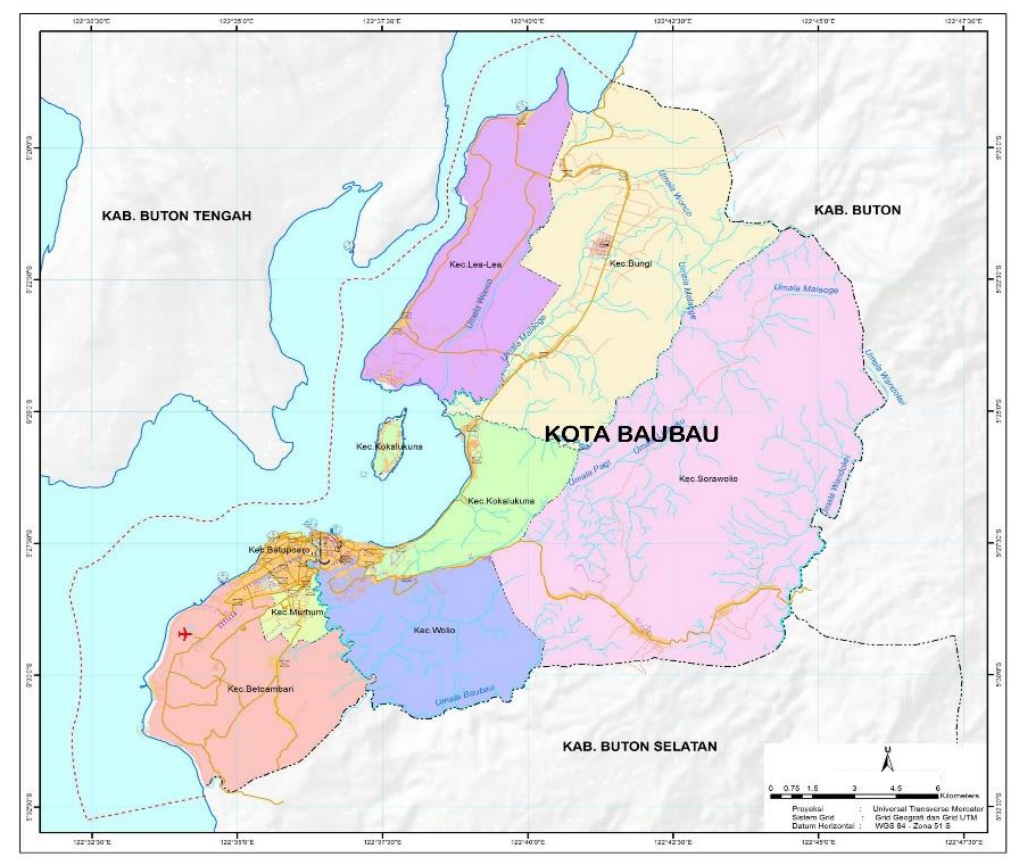

Sumber: Disalin dari Dinas Tata Kota dan Bangunan Kota Baubau, 2016

\section{Gambar 1. Peta Wilayah Administrasi Kota Baubau}

\section{Pendekatan Penelitian}

Pembangunan di wilayah pesisir Kota Baubau diharapkan mengacu pada konsep pembangunan berkelanjutan, sebagaimana termuat dalam Report of the World Commission on Environment and Development yang mendefinisikan pembangunan berkelanjutan sebagai pembangunan untuk memenuhi kebutuhan umat manusia saat ini, tanpa menurunkan atau menghancurkan kemampuan generasi mendatang dalam memenuhi kebutuhannya (Brundtland Commission, 1987).

Aspek pembangunan berkelanjutan meliputi ekologi, ekonomi, dan sosial (Brundtland Commission, 1987). Dalam konteks pembangunan berkelanjutan di wilayah pesisir, maka perlu memasukkan aspek hukum dan kelembagaan (Dahuri, 2003; Kay \& Alder, 1999; Wibowo, 2009). Dalam perkembangannya, untuk kasus kota tepian pantai, Bohari (2010) dan Laras, Marimin, Nurjaya, \& Budiharso (2011) menambahkan aspek infrastruktur dan teknologi.

Penelitian ini menilai status keberlanjutan pembangunan Kota Baubau sebagai kota yang orientasi pembangunannya di wilayah pesisir. Mengacu pada beberapa literatur, serta melihat kondisi eksisting lokasi penelitian, maka dimensi pembangunan yang akan diteliti meliputi dimensi ekonomi, ekologi, sosial, infrastruktur dan teknologi, serta hukum dan kelembagaan. Masing-masing dimensi memiliki atribut dan kriteria tersendiri yang 
mencerminkan keberlanjutan dari setiap dimensi pada lokasi penelitian. Penentuan atribut pada setiap dimensi ditentukan berdasarkan studi/penelusuran pustaka dan konsultasi pakar/pemangku kepentingan pada lokasi penelitian. Adapun penentuan bobot setiap atribut melalui studi pustaka, konsultasi pakar/pemangku kepentingan, dan scientific judgement.

\section{Jenis dan Sumber Data}

Jenis dan sumber data yang akan digunakan dalam penelitian ini terdiri atas data primer dan sekunder. Data primer bersumber dari informan yang merupakan pihak/pemangku kepentingan yang terkait dengan pembangunan di wilayah pesisir Kota Baubau dengan menggunakan kriteria sebagai berikut:

(1) mempunyai pengalaman yang kompeten sesuai bidang yang dikaji;

(2) memiliki kedudukan/jabatan dalam kompetensinya dengan bidang yang dikaji; dan

(3) bersedia, dan atau berada pada lokasi yang dikaji.

Berdasarkan kriteria tersebut, dipilih 22 informan yang terdiri atas: empat orang dari Badan Perencanaan dan Pembangunan Daerah (BAPPEDA) Kota Baubau, empat orang dari Dinas Kelautan dan Perikanan (DKP) Kota Baubau, satu orang dari Badan Penelitian dan Pembangunan Daerah (Balitbangda) Kota Baubau, satu orang dari Badan Pengendalian Dampak Lingkungan Daerah (Bapedalda) Kota Baubau, satu orang dari Dinas Kebudayaan dan Pariwisata (Disbudpar) Kota Baubau, satu orang dari Dinas Perindustrian, Perdagangan, dan Koperasi (Disperindakop) Kota Baubau, satu orang dari Dinas Kesehatan (Dinkes) Kota Baubau, satu orang dari Perusahaan Daerah Air Minum (PDAM) Kota Baubau, enam orang dari Kelompok Nelayan, dan dua orang dari pengusaha perikanan.

Adapun data sekunder bersumber dari dokumen/laporan terkait kajian penelitian, berupa Rencana Pembangunan Jangka Menengah Daerah (RPJMD) Kota Baubau, Peta Rencana Tata Ruang Wilayah (RTRW) Kota Baubau, Dokumen Rencana Strategis Wilayah Pesisir dan Laut Kota Baubau, Buku Data dan Analisa Penyusunan Rencana Zonasi Wilayah Pesisir dan Pulau-Pulau Kecil Kota Baubau, Laporan Status Lingkungan Hidup Kota Baubau, dan Statistik Daerah Kota Baubau.

\section{Analisis Data}

\section{Analisis Keberlanjutan}

Analisis keberlanjutan menggunakan analisis multidimensional scaling, analisis leverage, analisis Pareto, analisis Monte Carlo, penentuan nilai stress dan nilai koefisien determinasi $\left(\mathrm{R}^{2}\right)$.

\section{Multidimensional Scaling (MDS) Analysis}

Pemilihan multidimensional scaling (MDS) dalam analisis rapfish ini dilakukan berhubung hasil yang diperoleh terbukti lebih stabil dari metode multivariate analysis yang lain, seperti factor analysis dan multi-attribute utility theory (Pitcher \& Preikshot, 2001). Pada penggunaan analisis MDS, objek atau titik yang diamati dipetakan ke dalam ruang dua atau tiga dimensi, sehingga objek atau titik tersebut diupayakan ada sedekat mungkin dari titik asal. Teknik ordinasi (penentuan jarak) di dalam MDS didasarkan pada Euclidian Distance yang dalam ruang berdimensi $n$ dapat ditulis sebagai persamaan (1) (Fauzi \& Anna, 2002). 


$$
d=\sqrt{\left(\left|x_{1}-x_{2}\right|^{2}+\left|y_{1}-y_{2}\right|^{2}\left|z_{1}-z_{2}\right|^{2}+\ldots \ldots\right)} .
$$

Titik tersebut kemudian dibulatkan dengan meregresikan jarak euclidian $\left(d_{i j}\right)$ dari titik $i$ ke titik $j$ dengan titik asal $\left(d_{i j}\right)$ dengan persamaan (2), berikut ini:

$$
d_{i j}=a+\beta \delta_{i j}+\varepsilon
$$

Dalam meregresikan persamaan tersebut digunakan teknik least squared bergantian yang didasarkan pada akar dari Euclidian Distance (squared distance) atau disebut algoritma ALSCAL, dengan prinsip membuat pengulangan (iteration) proses regresi tersebut sehingga mampu menghasilkan nilai error terkecil. Menurut Kavanagh (2001), algoritma ALSCAL mengoptimasi jarak kuadrat (squared distance $=d_{i j k}$ ) terhadap data kuadrat (titik asal $=O_{i j k}$ ), dalam tiga dimensi $(i, j, k)$ ditulis dalam formula yang disebut $S$ Stress, seperti yang tertulis pada persamaan (3).

$$
\mathrm{S}=\sqrt{\frac{1}{\mathrm{~m}} \sum_{\mathrm{k}=1}^{\mathrm{m}}\left[\frac{\sum_{\mathrm{i}} \sum_{\mathrm{j}}\left(\mathrm{d}_{\mathrm{ijk}}^{2} \mathrm{o}_{2 \mathrm{jk}}^{2}\right)^{2}}{\sum_{\mathrm{i}} \sum_{\mathrm{j}} \mathrm{o}_{\mathrm{ijk}}^{4}}\right]}
$$

dengan jarak kuadrat merupakan jarak Euclidian yang dibobot, maka dapat ditulis sebagaimana persamaan (4).

$$
\mathrm{d}_{\mathrm{ijk}}^{2}=\sum_{\mathrm{a}=1}^{\mathrm{i}} \mathrm{w}_{\mathrm{ka}}\left(\mathrm{x}_{\mathrm{ia}}-\mathrm{x}_{\mathrm{ja}}\right)^{2}
$$

Melalui metode MDS, posisi titik keberlanjutan dapat divisualisasikan melalui sumbu horizontal dan sumbu vertikal. Adanya proses rotasi, maka posisi titik dapat divisualisasikan pada sumbu horizontal dengan nilai indeks keberlanjutan diberi nilai skor 0\% (Buruk) dan 100\% (Baik). Selanjutnya nilai indeks keberlanjutan setiap dimensi dapat divisualisasikan dalam bentuk diagram layang-layang (kite diagram). Nilai skor yang merupakan nilai indeks keberlanjutan setiap dimensi dapat dilihat pada Tabel 1.

Tabel 1. Kategori Keberlanjutan Berdasarkan Nilai Indeks Hasil Analisis MDS

\begin{tabular}{cc}
\hline Nilai Indeks & Kategori \\
\hline $00,00-25,59$ & Buruk (Tidak Berkelanjutan) \\
$26,00-49,99$ & Kurang (Kurang Berkelanjutan) \\
$50,00-74,99$ & Cukup (Cukup Berkelanjutan) \\
$75,00-100,00$ & Baik (Berkelanjutan) \\
\hline
\end{tabular}

Sumber: Analisis Penulis, 2016

\section{Monte Carlo Analysis}

Analisis ini digunakan untuk menguji tingkat kepercayaan nilai indeks masing-masing dimensi dengan tingkat kepercayaan 95\%. Analisis Monte Carlo membantu dalam analisis keberlanjutan untuk melihat pengaruh kesalahan pembuatan skor pada setiap atribut yang disebabkan oleh kesalahan prosedur atau pemahaman terhadap atribut dan variasi pemberian skor karena perbedaan opini atau penilaian yang berbeda oleh peneliti, stabilitas proses analisis MDS, kesalahan memasukkan data atau data yang hilang, dan nilai stress yang terlalu tinggi (Kavanagh, 2001). 


\section{Leverage Analysis}

Penentuan faktor pengungkit (leverage factors) yang merupakan faktor-faktor strategis keberlanjutan dimasa depan menggunakan analisis leverage. Leverage merupakan analisis yang menggambarkan sensitivitas/kepekaan setiap atribut terhadap nilai keberlanjutan dan digunakan untuk mengetahui atribut-atribut yang sensitif. Semakin besar perubahan nilai Root Mean Square (RMS), maka semakin sensitif atribut tersebut terhadap keberlanjutan.

\section{Pareto Analysis}

Konsep Pareto disebut kaidah 80-20, adalah bahwa 80\% kegiatan disebabkan oleh $20 \%$ faktor. Dengan berfokus pada $20 \%$ faktor maka akan dapat mengatasi $80 \%$ persoalannya. Penggunaan analisis Pareto dalam penelitian ini akan disesuaikan dengan kebutuhan penelitian dan tetap mengacu pada nilai indeks keberlanjutan pada Tabel 1. Pengadopsian Hukum Pareto pada penelitian ini tidak pada kaidah 80-20, tetapi pada kaidah 75-25, yaitu atribut dengan batas nilai kumulatif $<75 \%$ merupakan atribut yang sensitif berpengaruh terhadap nilai indeks keberlanjutan.

\section{Nilai Stress dan Nilai Koefisien Determinasi $\left(R^{2}\right)$}

Untuk mengetahui apakah atribut-atribut yang dikaji dalam analisis MDS cukup akurat dan dapat dipertanggungjawabkan secara ilmiah, maka dapat dilihat dari nilai stress dan nilai koefisien determinasi $\left(\mathrm{R}^{2}\right)$. Menurut Kavanagh \& Pitcher (2004), hasil analisis dianggap akurat dan dapat dipertanggungjawabkan apabila memiliki nilai stress lebih kecil dari 0,25 (25\%) dan nilai koefisien determinasi (R) mendekati nilai 1,0 (100\%).

\section{Hasil dan Pembahasan}

\section{Analisis Multidimensional Scalling dan Analisis Monte Carlo}

Analisis ordinasi (MDS) menunjukkan bahwa status keberlanjutan bervariasi pada setiap dimensi (Tabel 2).

Tabel 2. Nilai Ordinasi Dimensi Keberlanjutan Pembangunan Kota Baubau

\begin{tabular}{lcccc}
\hline \multirow{2}{*}{ Dimensi Keberlanjutan } & \multicolumn{2}{c}{ Indeks Keberlanjutan } & \multirow{2}{*}{ Perbedaan } & \multirow{2}{*}{ Kategori } \\
\cline { 2 - 3 } & MDS & Monte Carlo & & \\
\hline Ekologi & 32,90 & 33,78 & 0,88 & Kurang Berkelanjutan \\
Ekonomi & 41,87 & 42,48 & 0,61 & Kurang Berkelanjutan \\
Sosial & 20,61 & 22,85 & 2,24 & Tidak Berkelanjutan \\
Infrastruktur dan Teknologi & 74,77 & 73,38 & 1,39 & Cukup Berkelanjutan \\
Hukum dan Kelembagaan & 65,87 & 63,90 & 1,97 & Cukup Berkelanjutan \\
Multidimensi & 47,20 & 47,28 & 0,08 & Kurang Berkelanjutan \\
\hline Sumber: Analisis Penulis, 2016 & & & &
\end{tabular}

Berdasarkan Tabel 2 diketahui bahwa dimensi ekologi dan ekonomi Kota Baubau berada pada kategori kurang berkelanjutan, sedangkan pada dimensi infrastruktur dan teknologi serta hukum dan kelembagaan berada pada kategori cukup berkelanjutan. Adapun pada dimensi sosial berada dalam kategori tidak berkelanjutan. Secara keseluruhan (multidimensi), status pembangunan Kota Baubau berada pada kategori kurang berkelanjutan (47,20). Hasil analisis MDS dan analisis Monte Carlo menghasilkan perbedaan sangat kecil, yaitu tidak lebih dari 5\% (Tabel 2). Hal ini menunjukkan tingkat 
kepercayaan terhadap nilai indeks setiap dimensi dan pengaruh kesalahan yang dapat mempengaruhi proses analisis.

\section{Analisis Leverage dan Analisis Pareto}

\section{Dimensi Ekologi}

Analisis leverage (Gambar 2) dan analisis Pareto (Gambar 3) menunjukkan tujuh atribut yang sensitif $(<75 \%)$ berpengaruh terhadap nilai indeks keberlanjutan dimensi ekologi, yaitu: tingkat penyimpangan penggunaan lahan, keanekaragaman fitoplankton, keanekaragaman zooplankton, tutupan mangrove, volume sampah, luas ruang terbuka hijau (RTH), dan jumlah jenis ikan yang ditangkap.

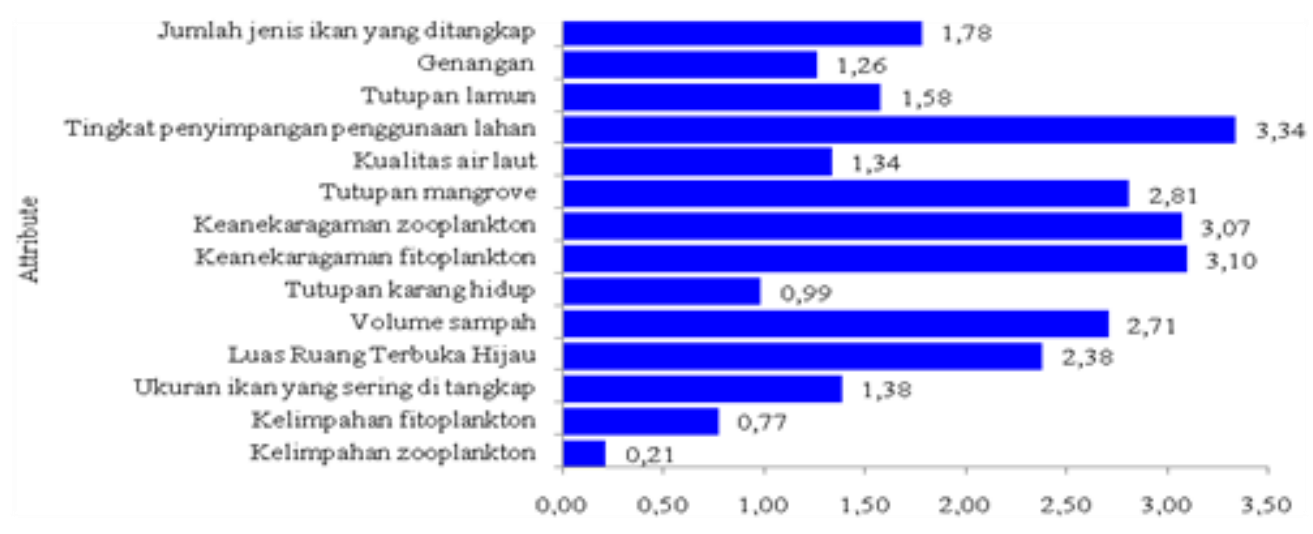

Sumber: Hasil olahan data primer dan sekunder menggunakan Rapfish, 2016

\section{Gambar 2. Diagram Leverage Dimensi Ekologi}

Hasil evaluasi penggunaan lahan oleh Fahmi, Sitorus, \& Fauzi (2016) menunjukkan bahwa tingkat penyimpangan penggunaan lahan terhadap rencana pola ruang Kota Baubau berada pada kategori rendah. Penggunaan lahan di Kota Baubau cenderung menjadi lahan terbangun karena memiliki nilai ekonomi lebih tinggi. Menurut Fahimuddin, Barus, \& Mulatsih (2016), kecenderungan ini dapat mengancam keberlanjutan kota jika aspek ekologis diabaikan dalam perencanaan tata guna lahan diperkotaan. Untuk itu, pengelolaan lahan di Kota Baubau diarahkan pada upaya pengendalian lahan terbangun dan perlindungan lahan pertanian dan hutan.

Nilai indeks keanekaragaman fitoplankton dan zooplankton diperairan Baubau masing-masing adalah 0,93 dan $0,98\left(\mathrm{H}^{\prime}<1\right)$, yang berarti keanekaragaman rendah, menandakan adanya tekanan ekologis sangat tinggi pada perairan. Kondisi ini diduga turut mempengaruhi jumlah jenis ikan yang ditangkap sebagai atribut sensitif. Rendahnya indeks keanekaragaman fitoplankton dan zooplankton diduga turut mempengaruhi jumlah jenis ikan di perairan Baubau. 


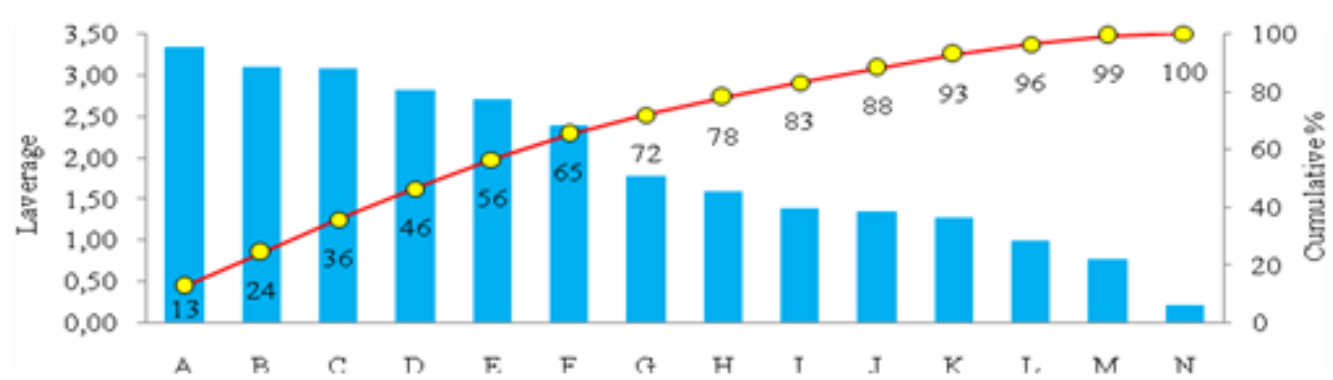

Keterangan: A) Tingkat penyimpangan penggunaan lahan, B) Keanekaragaman fitoplankton, C) Keanekaragaman zooplankton, D) Tutupan mangrove, E) Volume sampah, F) Luas Ruang Terbuka Hijau, G) Jumlah jenis ikan yang ditangkap, H) Tutupan lamun, I) Ukuran ikan yang sering ditangkap, J) Kualitas air laut, K) Genangan, L) Tutupan karang hidup, M) Kelimpahan fitoplankton, N) Kelimpahan zooplankton.

Sumber: Hasil uji lanjut nilai leverage menggunakan Microsoft Excel (Uji Pareto), 2016

\section{Gambar 3. Diagram Pareto Dimensi Ekologi}

Tutupan mangrove di Kota Baubau berada pada kisaran rendah (20\%-40\%). Ekosistem mangrove di Kota Baubau berada dalam tekanan ekologis yang tinggi. Hal ini terkait erat dengan tingginya aktivitas masyarakat dan pembangunan di wilayah pesisir Kota Baubau.

Penyumbang sampah terbanyak di Kota Baubau adalah rumah tangga/permukiman penduduk, sisanya berasal dari non permukiman. Kota Baubau menghasilkan timbunan sampah sebesar $332,82 \mathrm{~m}^{3} /$ hari/154.800 orang/hari atau $0,00215 \mathrm{~m}^{3} /$ orang/hari $(2.15$ L/orang/hari). Angka ini sudah melebihi SNI untuk satuan timbunan sampah untuk kategori kota sedang.

Keseluruhan luas RTH Kota Baubau pada tahun 2016 sebesar 5.049 ha (BAPEDALDA Kota Baubau, 2016) dari 36.596 ha (luas Kota Baubau) atau 13,80\%. Luasan ini masih berada dibawah luas RTH ideal yang ditetapkan oleh Undang-undang No. 26 tahun 2007 tentang Penataan Ruang, yaitu sebesar 30\% dari luas wilayah kota.

\section{Dimensi Ekonomi}

Berdasarkan hasil analisis leverage (Gambar 4) dan analisis Pareto (Gambar 5), terdapat tujuh atribut yang sensitif $(<75 \%)$ berpengaruh terhadap nilai indeks keberlanjutan dimensi ekonomi, yaitu: Tingkat Kesempatan Kerja (TKK), Tingkat Pengangguran Terbuka (TPT), jumlah tenaga kerja industri, persentase keluarga miskin, nilai investasi industri, jumlah industri, produksi perikanan.

Angka TPT Kota Baubau tahun 2015 adalah sebesar 7,17\%, meningkat dari tahun 2014 yang hanya 6,79\%. Sementara itu TKK dari tahun 2014 ke 2015 mengalami penurunan dari $93,21 \%$ menjadi $92,83 \%$. Hal ini menunjukkan bahwa Pemerintah Kota Baubau perlu menciptakan lapangan kerja baru untuk penduduk usia kerja yang belum terserap di pasar kerja.

Jumlah industri pengolahan di Kota Baubau mengalami sedikit penurunan pada tahun 2015 yaitu menjadi 1.818 perusahaan dari 1.821 perusahaan pada tahun sebelumnya. Penurunan jumlah perusahaan ini menyebabkan turunnya jumlah tenaga kerja yang terserap dan turunnya nilai investasi pada sektor industri. 


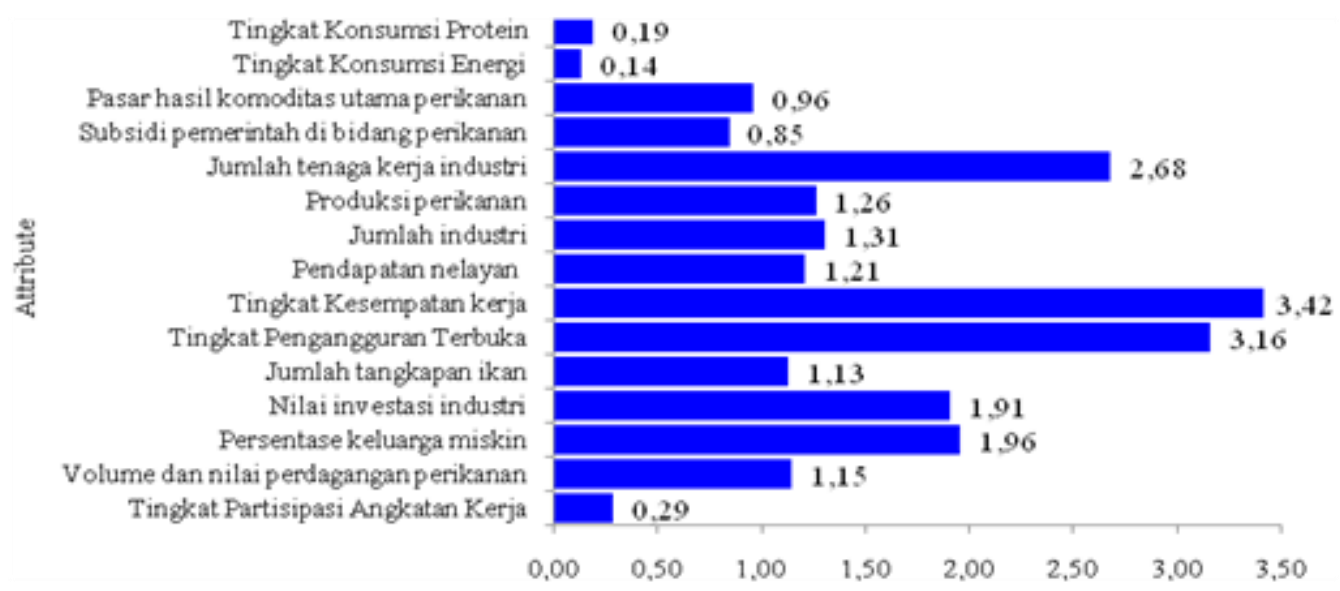

Sumber: Hasil olahan data primer dan sekunder menggunakan Rapfish, 2016

\section{Gambar 4. Diagram Leverage Dimensi Ekonomi}

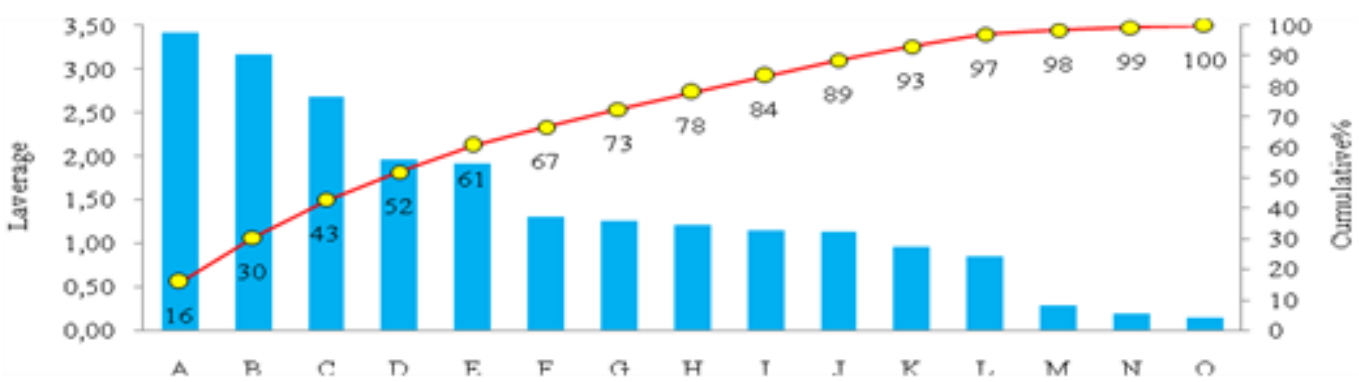

Keterangan: A) Tingkat kesempatan kerja (TKK), B) Tingkat pengangguran terbuka (TPT), C) Jumlah tenaga kerja industri, D) Persentase keluarga miskin, E) Nilai investasi industri, F) Jumlah industri, G) Produksi perikanan, H) Pendapatan nelayan, I) Volume dan nilai perdagangan perikanan, J) Jumlah tangkapan ikan, K) Pasar hasil komoditas utama perikanan, L) Subsidi pemerintah di bidang perikanan, M) Tingkat partisipasi angkatan kerja (TPAK), N) Tingkat konsumsi protein, O) Tingkat konsumsi energi.

Sumber: Hasil uji lanjut nilai leverage menggunakan Microsoft Excel (Uji Pareto), 2016

\section{Gambar 5. Diagram Pareto Dimensi Ekonomi}

Kondisi tersebut di atas berdampak pada masih tingginya keluarga miskin di Kota Baubau. Persentase keluarga miskin di Kota Baubau menunjukkan tren positif yang ditunjukkan dengan penurunan antara tahun 2012-2015. Meski mengalami tren positif, masih tingginya keluarga miskin menunjukkan bahwa tugas pemerintah daerah belum selesai dalam hal penuntasan kemiskinan di Kota Baubau.

Produksi perikanan di Kota Baubau mengalami fluktuasi selama periode 2010-2014. Apabila dilihat dari potensi yang dimiliki, Kota Baubau memiliki potensi perikanan yang bisa ditingkatkan lagi. Kondisi ini didukung oleh hasil penelitian Jamilah (2013) yang menunjukkan bahwa perairan Kota Baubau yang sesuai untuk budidaya rumput laut seluas 196,63 Ha dengan kapasitas lahan tersedia adalah 152,30 Ha. Estimasi unit media budidaya rumput laut sebanyak 524 unit dengan prakiraan produksi berkisar antara 943,82 - 1415,74 ton/tahun. Pemanfaatan potensi kelautan merupakan suatu peluang untuk meningkatkan kondisi ekonomi masyarakat yang relatif masih rendah (Rizal, 2013). Menurut Sudarya, 
Sitorus, \& Firdaus (2013), wilayah pesisir secara umum memiliki basis ekonomi yang kuat disektor primer yaitu perikanan dan pada sektor sekunder adalah sektor industri pengolahan.

\section{Dimensi Sosial}

Berdasarkan hasil analisis leverage (Gambar 6) dan analisis Pareto (Gambar 7), terdapat tujuh atribut yang sensitif $(<75 \%)$ berpengaruh terhadap nilai indeks keberlanjutan dimensi sosial, yaitu: tingkat kesehatan, persebaran penduduk, jumlah peserta KB, kriminalitas, kepadatan penduduk, rasio ketergantungan penduduk, dan rasio jenis kelamin.

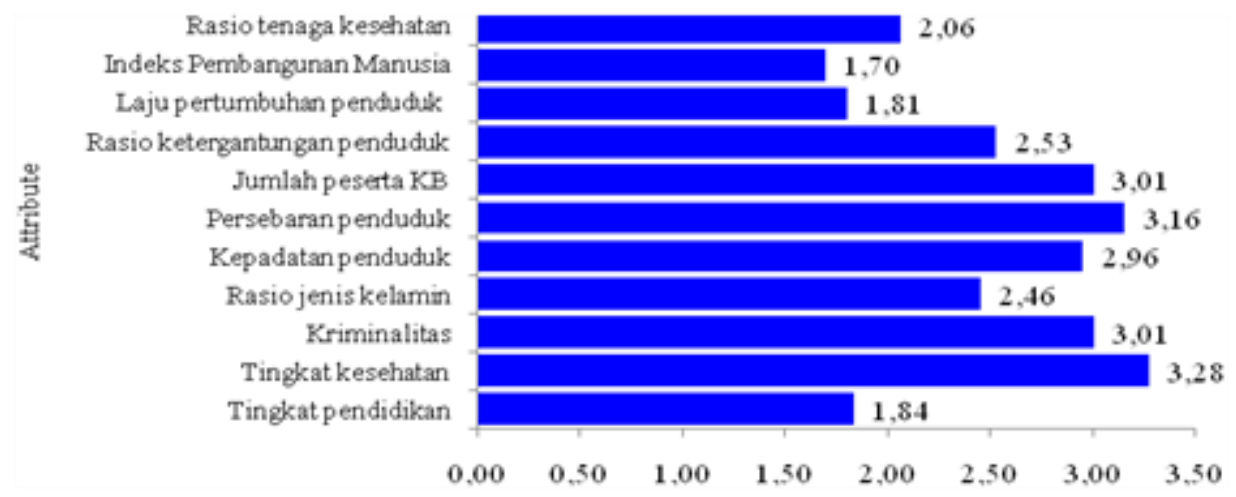

Sumber: Hasil uji lanjut nilai leverage menggunakan Microsoft Excel (Uji Pareto), 2016

\section{Gambar 6. Diagram Leverage Dimensi Sosial}

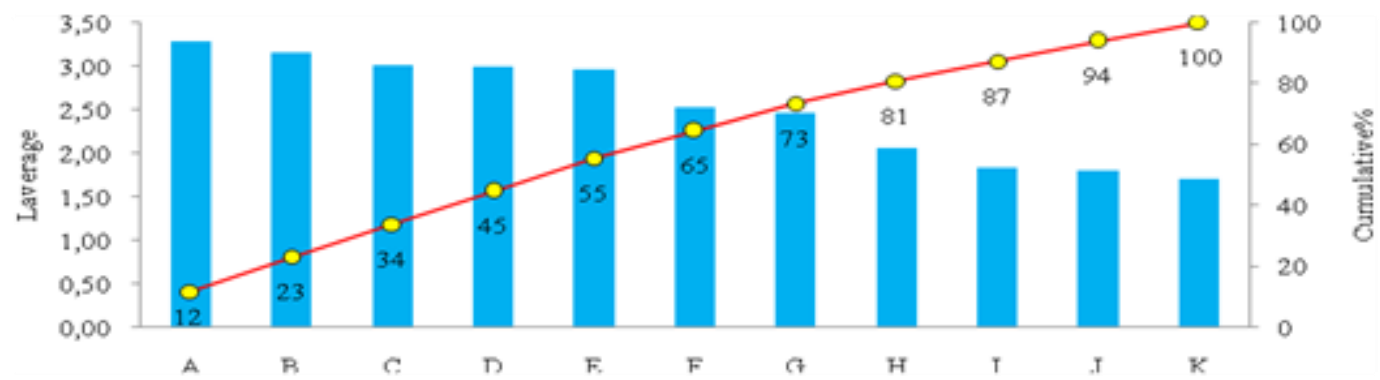

Keterangan: A) Tingkat kesehatan, B) Persebaran penduduk, C) Jumlah peserta Keluarga Berencana (KB), D) Kriminalitas, E) Kepadatan penduduk, F) Rasio ketergantungan penduduk, G) Rasio jenis kelamin, H) Rasio tenaga kesehatan, I) Tingkat pendidikan, J) Laju pertumbuhan penduduk, K) Indeks Pembangunan Manusia (IPM).

Sumber: Hasil uji lanjut nilai leverage menggunakan Microsoft Excel (Uji Pareto), 2016

\section{Gambar 7. Diagram Pareto Dimensi Sosial}

Persebaran penduduk, jumlah peserta KB, kriminalitas, kepadatan penduduk, rasio ketergantungan penduduk, dan rasio jenis kelamin merupakan masalah yang perlu mendapatkan perhatian pemerintah. Jumlah peserta KB antara periode tahun 2013-2015 mengalami penurunan. Kondisi ini berdampak jelas pada tingginya laju pertumbuhan penduduk selama tiga tahun terakhir $(2,00 \%-4,32 \%)$, dengan tingkat kelahiran didominasi jenis kelamin perempuan. Kondisi ini menjadi alasan sex ratio Kota Baubau nilainya lebih kecil dari 100 yaitu 97,34\%. 
Persebaran penduduk yang tidak merata berdampak pada kepadatan penduduk yang tidak ideal antar kecamatan. Oleh karena itu, persebaran penduduk harus merata disetiap kecamatan guna mengurangi penduduk pada lokasi tertentu, sebab kepadatan penduduk juga rentan terhadap konflik sosial/kriminalitas. Hal ini ditunjukkan dari angka kriminalitas di Kota Baubau yang mengalami peningkatan antara tahun 2013-2015. Sementara itu, rasio ketergantungan penduduk (Dependency Ratio) tergolong tinggi ( $>41 \%$ ) yaitu sebesar $55,70 \%$, menunjukkan bahwa setiap 100 orang usia produktif menanggung atau membiayai sekitar 55 orang usia tidak produktif.

Tingkat kesehatan masyarakat mengalami fluktuasi antara tahun 2013-2015. Perbaikan kesehatan yang dicanangkan pemerintah melalui pemberantasan berbagai macam penyakit harus lebih ditingkatkan lagi melalui peningkatan pelayanan kesehatan seperti penyuluhan dan pemberian informasi kepada masyarakat terkait Pola Hidup Bersih dan Sehat (PHBS), serta melakukan perbaikan sanitasi masyarakat.

\section{Dimensi Infrastruktur dan Teknologi}

Berdasarkan hasil analisis leverage (Gambar 8) dan analisis Pareto (Gambar 9), terdapat tujuh atribut yang sensitif $(<75 \%)$ berpengaruh terhadap nilai indeks keberlanjutan dimensi infrastruktur dan teknologi, yaitu: Tempat Pelelangan Ikan (TPI), Stasiun Pengisian Bahan Bakar Nelayan (SPBN), banyaknya air minum yang disalurkan, pelabuhan laut, persentase rumah tangga menurut fasilitas MCK sendiri, pelabuhan penyeberangan antar pulau, dan rumah tangga menurut kualitas perumahan.

Kurangnya fasilitas TPI seperti belum tersedianya cool storage dengan kapasitas besar dan memadai dan cool box serta persediaan es batu yang cukup (kontinyu) menyebabkan hasil tangkapan tidak dapat dikelola dengan baik pada musim-musim puncak penangkapan. Bahan bakar bagi nelayan merupakan kebutuhan penting untuk operasionalisasi kapal nelayan, sehingga atribut SPBN ikut menjadi atribut yang sensitif pada dimensi ini. Kondisi pelabuhan laut masih perlu dibenahi untuk memaksimalkan peranan pelabuhan dalam menopang sektor perdagangan di Kota Baubau. Sementara kondisi pelabuhan penyeberangan antarpulau masih memerlukan beberapa pembenahan seperti terminal/ruang tunggu, tempat bersandar kapal, serta kondisi di beberapa pelabuhan penyeberangan yang secara fisik mulai rusak dan membutuhkan perbaikan.

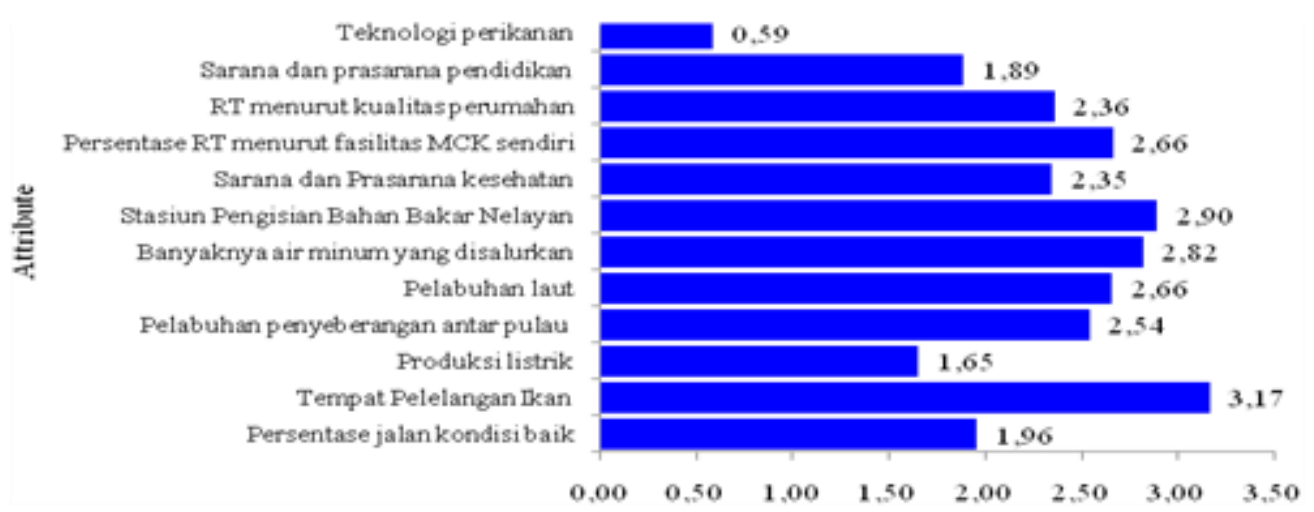

Sumber: Hasil uji lanjut nilai leverage menggunakan Microsoft Excel (Uji Pareto), 2016

Gambar 8. Diagram Leverage Dimensi Infrastruktur dan Teknologi 


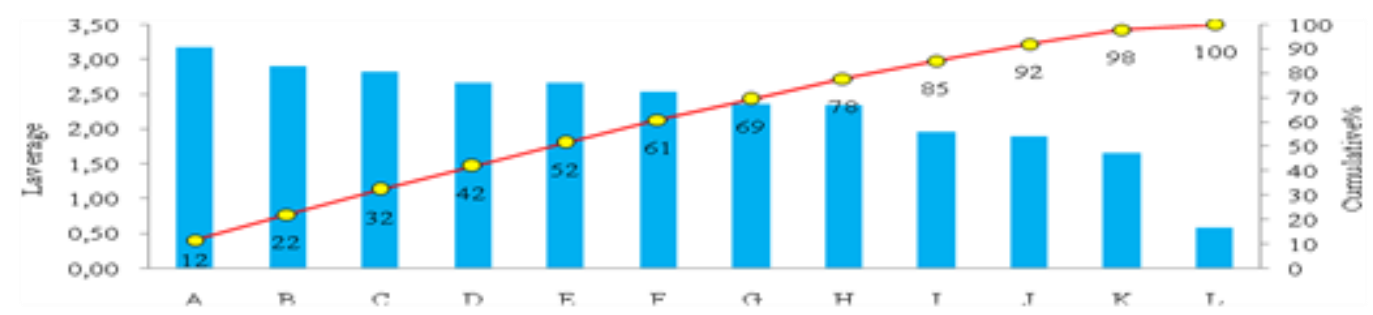

Keterangan: A) Tempat Pelelangan Ikan (TPI), B) Stasiun Pengisian Bahan Bakar Nelayan (SPBN), C) Banyaknya air minum yang disalurkan, D) Pelabuhan laut, E) Persentase rumah tangga menurut fasilitas MCK sendiri, F) Pelabuhan penyeberangan antarpulau, G) Rumah tangga menurut kualitas perumahan, H) Sarana kesehatan, I) Persentase jalan kondisi baik, J) Sarana pendidikan, K) Produksi listrik, L) Teknologi perikanan.

Sumber: Hasil uji lanjut nilai leverage menggunakan Microsoft Excel (Uji Pareto), 2016

\section{Gambar 9. Diagram Pareto Dimensi Infrastruktur dan Teknologi}

Seiring dengan tingginya laju pertumbuhan penduduk, kebutuhan air bersih terus meningkat setiap tahunnya. Masih adanya satu kecamatan yang belum merasakan pelayanan air bersih dari PDAM menjadi masalah tersendiri terkait pelayanan air bersih. Masalah perpipaan yang belum menjangkau seluruh wilayah juga masih menjadi kendala PDAM dalam menyalurkan air bersih. Rumah tangga (RT) menurut kualitas perumahan di Kota Baubau mengalami peningkatan yang cukup signifikan pada periode 2014-2015, dengan peningkatan antara 92,93\%-99,53\%. Jumlah RT yang memiliki fasilitas MCK mencapai 81,25\%, MCK bersama/umum 18,15\%, dan belum memiliki 0,60\%. Kondisi ini masih perlu ditingkatkan ditahun-tahun berikutnya agar seluruh penduduk Kota Baubau memiliki hunian yang berkualitas dengan fasilitas MCK memadai.

\section{Dimensi Hukum dan Kelembagaan}

Berdasarkan hasil analisis leverage (Gambar 10) dan analisis Pareto (Gambar 11), terdapat delapan atribut yang sensitif $(<75 \%)$ berpengaruh terhadap nilai indeks keberlanjutan dimensi hukum dan kelembagaan, yaitu: keberadaan kelompok nelayan, perlindungan dan rehabilitasi terhadap ekosistem pesisir, pembinaan dan penataan kawasan permukiman, ketersediaan produk hukum pengendalian pencemaran air, pengelolaan objek pariwisata bahari, ketersediaan dokumen renstra dan zonasi wilayah pesisir dan pulau-pulau kecil, konsistensi terhadap RTRW, dan konservasi sumberdaya air baku.

Keberadaan nelayan memegang peran yang penting berkaitan dengan terpenuhinya kebutuhan pangan (ketersediaan stok ikan) masyarakat Kota Baubau. Menurunnya luasan ekosistem mangrove, terumbu karang, dan lamun di wilayah pesisir Kota Baubau memerlukan perlindungan dan rehabilitasi terhadap ketiga ekosistem pesisir tersebut. Pembinaan pemerintah terhadap kawasan permukiman khususnya di kawasan pesisir diperlukan guna meminimalisasi dampak yang ditimbulkan oleh aktivitas permukiman tersebut seperti pembuangan limbah domestik yang masih banyak dibuang ke laut. Implementasi produk hukum pengendalian pencemaran air di Kota Baubau masih mengalami kendala dalam implementasinya. Kegiatan pemantauan dan pengukuran kualitas air juga belum dilakukan secara rutin dan berkesinambungan. 


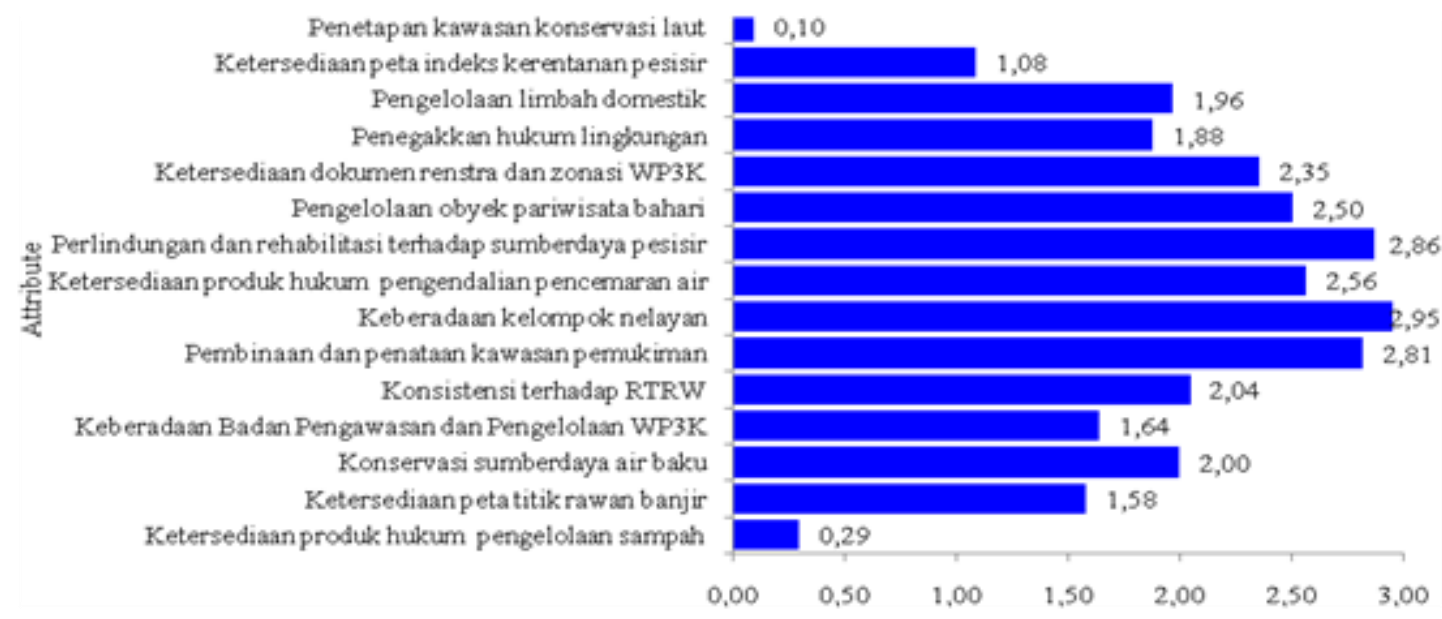

Sumber: Hasil uji lanjut nilai leverage menggunakan Microsoft Excel (Uji Pareto), 2016

Gambar 10. Diagram Leverage Dimensi Hukum dan Kelembagaan

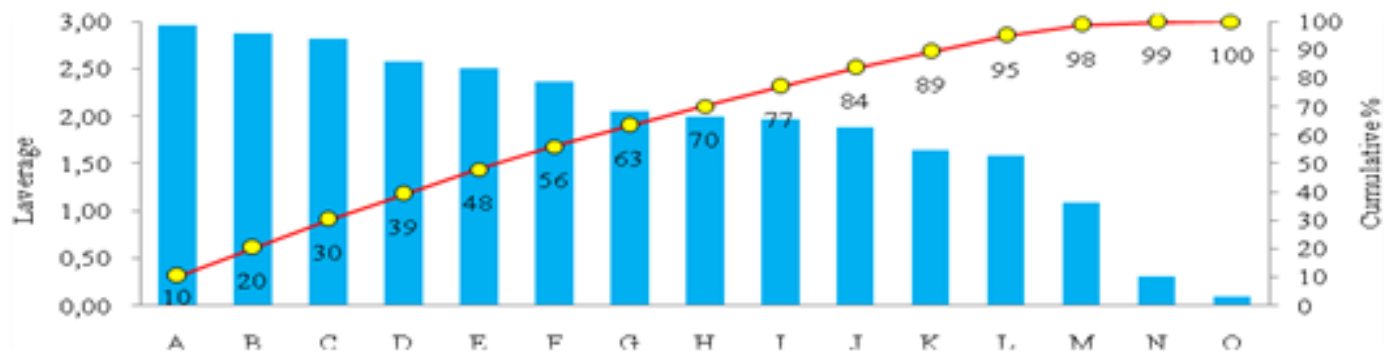

Keterangan: A) Keberadaan kelompok nelayan, B) Perlindungan dan rehabilitasi terhadap ekosistem pesisir, C) Pembinaan dan penataan kawasan permukiman, D) Ketersediaan produk hukum pengendalian pencemaran air, E) Pengelolaan objek pariwisata bahari, F) Ketersediaan dokumen Rencana Strategis dan Zonasi Wilayah Pesisir dan Pulau-pulau Kecil, G) Konsistesi terhadap Rencana Tata Ruang Wilayah, H) Konservasi sumber daya air baku, I) Pengelolaan limbah domestik, J) Penegakan hukum lingkungan, K) Keberadaan Badan Pengawasan dan Pengelolaan Wilayah Pesisir dan Pulau-pulau Kecil, L) Ketersediaan peta titik rawan banjir, M) Ketersediaan Peta Indeks Kerentanan Wilayah Pesisir dan Pulau-pulau Kecil, N) Ketersediaan produk hukum pengelolaan sampah, O) Penetapan kawasan konservasi laut.

Sumber: Hasil uji lanjut nilai leverage menggunakan Microsoft Excel (Uji Pareto), 2016

Gambar 11. Diagram Pareto Dimensi Hukum dan Kelembagaan

Pengelolaan wisata pantai dan bahari di Kota Baubau belum optimal, padahal sektor ini berpotensi untuk bisa dikembangkan. Hasil penelitian Santoso, Patandiana, \& Faiza (2012) menunjukkan bahwa Pantai Nirwana, Pantai Lakeba, dan Pantai Kokalukuna memiliki potensi sebagai wisata diving, wisata snorkeling, wisata renang, wisata olahraga pantai, wisata kuliner, wisata rekreasi, wisata memancing dan beberapa kegiatan wisata lainnya. Namun hingga saat ini, potensi wisata tersebut belum terkelola dengan baik, terbukti dengan belum adanya kontribusi dari pariwisata yang berarti bagi perekonomian daerah Kota Baubau.

RSWP3K dan RZWP3K yang telah dibuat diharapkan bisa diimpelementasikan guna meningkatkan kualitas kehidupan manusia serta kualitas ekosistem/lingkungan pesisir. Dalam hal penataan ruang, masih terdapat inkonsistensi terhadap RTRW. Faktor yang mempengaruhi inkonsistensi pemanfaatan penggunaan lahan terhadap rencana pola ruang 
adalah aksesibilitas, ketersediaan lahan pertanian, dan penambahan sarana dan prasarana dasar wilayah.

Kota Baubau memiliki potensi sumber daya air berupa sungai, mata air dan air tanah. Namun karena kurangnya kesadaran masyarakat, potensi sumber daya air yang awalnya merupakan cadangan air baku di Baubau menjadi tidak layak lagi untuk dikonsumsi. Oleh karena itu, diperlukan upaya konservasi sumber daya air baku.

\section{Nilai Stress dan Nilai Koefisien Determinasi $\left(R^{2}\right)$}

Nilai stress menunjukkan kisaran 0,12-0,13,sedangkan nilai koefisien determinasi ( $\left.\mathrm{R}^{2}\right)$ disetiap dimensi 0,95 (Tabel 3). Hasil ini menunjukkan bahwa semua atribut yang dikaji cukup akurat dan dapat dipertanggungjawabkan.

Tabel 3. Nilai Stress dan Koefisien Determinasi $\left(\mathbf{R}^{2}\right)$ Keberlanjutan Setiap Dimensi

\begin{tabular}{lccccc}
\hline \multirow{2}{*}{$\begin{array}{l}\text { Parameter } \\
\text { Statistik }\end{array}$} & Ekologi & Ekonomi & Sosial & $\begin{array}{c}\text { Infrastruktur dan } \\
\text { Teknologi }\end{array}$ & $\begin{array}{c}\text { Hukum dan } \\
\text { Kelembagaan }\end{array}$ \\
\cline { 2 - 5 } & 0,13 & 0,13 & 0,13 & 0,13 & 0,12 \\
Stress & 0,95 & 0,95 & 0,95 & 0,95 & 0,95 \\
\hline $\mathrm{R}^{2}$ & & &
\end{tabular}

Sumber: Analisis Penulis, 2016

Keragaman hasil keberlanjutan pada kelima dimensi dapat dilihat pada Gambar 12, yang menampilkan diagram keterkaitan antar dimensi. Bagian luar diagram menunjukkan skor baik (100\%) dan bagian dalam menunjukkan skor buruk (0\%). Pembangunan di Kota Baubau, meski cukup berkelanjutan pada dimensi infrastruktur dan teknologi serta hukum dan kelembagaan, namun belum memberikan pengaruh positif terhadap dimensi ekologi, ekonomi, dan sosial. Menurut Lubis (2011), dalam menata pembangunan kawasan pesisir perlu mempertimbangkan lima aspek, yaitu aspek keamanan dari bencana, aspek kenyamanan dalam ruang kota, aspek produktivitas yang ditandai dengan adanya lapangan kerja, aspek kualitas lingkungan hidup, dan aspek ketahanan terhadap perubahan iklim.

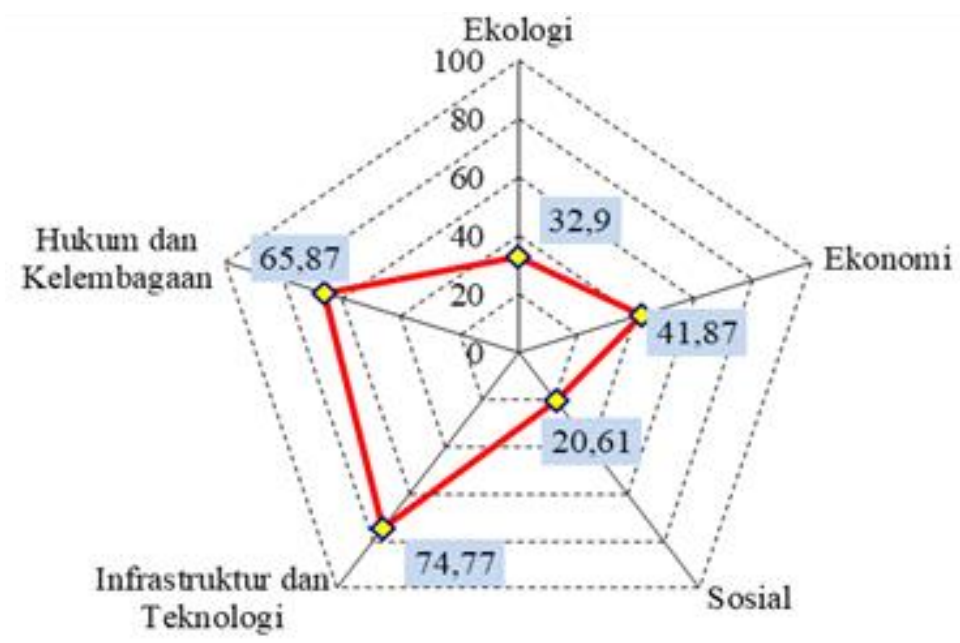

Sumber: Hasil Analisis MDS dalam bentuk Kite Diagram menggunakan Microsoft Excel, 2016

Gambar 12. Diagram Layang-layang Dimensi Keberlanjutan Kota Baubau 
Berdasarkan hasil penelitian, maka beberapa hal yang perlu mendapat perhatian pemerintah guna meningkatkan status keberlanjutan dimensi ekologi, ekonomi, dan sosial adalah: a) proses penyusunan Rencana Pola Ruang haruslah konsisten/taat asas kepada peraturan dan perundang-undangan yang berlaku, b) melakukan rehabilitasi terhadap ekosistem pesisir yang telah rusak dan melindungi yang masih dalam kondisi baik, c) implementasi produk hukum terkait pengendalian pencemaran air guna mengetahui dampak yang ditimbulkan oleh aktivitas masyarakat sehingga bisa dilakukan tindakan preventif dan perbaikan, d) melakukan pembinaan dan penataan terhadap kawasan permukiman, khususnya di wilayah pesisir dan bantaran sungai, e) melakukan konservasi terhadap sumber-sumber air baku, f) mengimplementasikan RSWP3K dan RZWP3K yang telah disusun dengan tetap melakukan pemantauan dan evaluasi dalam pelaksanaannya, $g$ ) memaksimalkan peran kelompok nelayan di setiap kecamatan pesisir guna meningkatkan produktivitas nelayan yang tentu saja bisa meningkatkan pendapatan dan kesejahteraan nelayan, h) melakukan kontrol terhadap laju pertumbuhan penduduk dengan cara memaksimalkan program KB yang selama ini masih berjalan belum maksimal, i) meningkatkan peran pariwisata dalam kegiatan ekonomi yang dapat menciptakan lapangan kerja serta kesempatan berusaha dengan tujuan untuk meningkatkan pendapatan masyarakat pesisir.

\section{Kesimpulan}

Kondisi keberlanjutan pembangunan Kota Baubau berdasarkan dimensi ekologi dan ekonomi berada dalam kategori kurang berkelanjutan, dimensi sosial berada dalam kategori tidak berkelanjutan, dimensi infrastruktur dan teknologi serta dimensi hukum dan kelembagaan berada dalam kategori cukup berkelanjutan.

Atribut sensitif yang berpengaruh terhadap keberlanjutan pembangunan Kota Baubau, yaitu tingkat penyimpangan penggunaan lahan, keanekaragaman fitoplankton, keanekaragaman zooplankton, tutupan mangrove, volume sampah, dan luas Ruang Terbuka Hijau, Tingkat Kesempatan Kerja, Tingkat Pengangguran Terbuka, jumlah tenaga kerja industri, persentase keluarga miskin, nilai investasi industri, jumlah industri, dan produksi perikanan, tingkat kesehatan, persebaran penduduk, jumlah peserta KB, kriminalitas, kepadatan penduduk, rasio ketergantungan penduduk, dan rasio jenis kelamin, Tempat Pelelangan Ikan, Stasiun Pengisian Bahan Bakar Nelayan, banyaknya air minum yang disalurkan, pelabuhan laut, persentase rumah tangga menurut fasilitas MCK sendiri, pelabuhan penyeberangan antar pulau, dan rumah tangga menurut kualitas perumahan, keberadaan kelompok nelayan, perlindungan dan rehabilitasi terhadap ekosistem pesisir, pembinaan dan penataan kawasan permukiman, ketersediaan produk hukum pengendalian pencemaran air, pengelolaan objek pariwisata bahari, ketersediaan dokumen renstra dan zonasi WP3K, konsistensi terhadap RTRW, konservasi sumber daya air baku.

\section{Ucapan Terima Kasih}

Penulis menyampaikan ucapan terima kasih yang tak terhingga kepada Dr. Dyah Rahmawati Hizbaron, S.Si.,M.T.,M.Sc. dan Dr. Djaka Marwasta, S.Si.,M.Si. yang telah berkenan untuk mengoreksi dan me-review demi kesempurnaan paper ini.

\section{Daftar Pustaka}

Badan Pengendalian Dampak Lingkungan Daerah Kota Baubau. (2016). Laporan Status Lingkungan Hidup Kota Baubau Tahun 2016. Baubau.

Badan Perencanaan dan Pembangunan Daerah Kota Baubau. (2015). Buku Data Kota Baubau. Baubau: Badan 


\section{Analisis Keberlanjutan Pembangunan Kota Tepian Pantai...}

Perencanaan dan Pembangunan Daerah Kota Baubau.

Badan Pusat Statistik Kota Baubau. (2016). Statistik Daerah Kota Baubau 2016. Baubau: Badan Pusat Statistik Kota Baubau.

Bohari, R. (2010). Model Kebijakan Pengelolaan Wilayah Pesisir Secara Terpadu dan Berkelanjutan di Pantai Makassar Sulawesi Selatan. Institut Pertanian Bogor.

Brundtland Commission. (1987). Our Common Future: Report of the World Commission on Environment and Development. The World Commission on Environment and Development (Vol. 4). Oxford: Oxford University Press.

Dahuri, R. (2003). Keanekaragaman Hayati Laut Aset Pembangunan Berkelanjutan Indonesia. Jakarta: Gramedia Pustaka Utama.

Dinas Kelautan dan Perikanan Kota Baubau. (2014). Laporan Akhir Penyusunan Dokumen Rencana Strategis (Renstra) Wilayah Pesisir dan Laut Kota Baubau 2014-2034. Baubau.

Effendi, M. (2009). Pengelolaan wilayah pesisir secara terpadu: Solusi pemanfaatan ruang, pemanfaatan sumber daya dan pemanfaatan kapasitas asimilasi wilayah pesisir yang optimal dan berkelanjutan. Jurnal Kelautan, 2(1), 81-86. Retrieved from http://journal.trunojoyo.ac.id/jurnalkelautan/article/view/906/0.

Fahimuddin, M. M., Barus, B., \& Mulatsih, S. (2016). Analisis daya dukung lahan di Kota Baubau, Sulawesi Tenggara. Tata Loka, 18(3), 183-196. doi: 10.14710/tataloka.18.3.183-196.

Fahmi, F., Sitorus, S. R. P., \& Fauzi, A. (2016). Evaluasi pemanfaatan penggunaan lahan berbasis rencana pola ruang Kota Baubau, Provinsi Sulawesi Tenggara. Tata Loka, 18(1), 27-39. doi: 10.14710/tataloka.18.1.27-39.

Fauzi, A., \& Anna, S. (2002). Evaluasi status berkelanjutan pembangunan perikanan, aplikasi RAPFISH, Studi Kasus Perairan Pesisir DKI Jakarta. Jurnal Pesisir dan Lautan, 4(3), 43-55.

Jamilah, J. (2013). Analisis kesesuaian lahan dan daya dukung lingkungan untuk budidaya rumput laut di perairan Baubau. Jurnal Biology Science \& Education, 2(1), 103-108. Retrieved from http://ejurnal.lp2m-iainambon.id/index.php/biosel/article/view/244.

Kavanagh, P. (2001). Rapid Appraisal of Fisheries (RAPFISH) Project. RAPFISH Software Description (For Microsoft Excel. Vancouver: University of British Columbia.

Kavanagh, P. F., \& Pitcher, T. J. (2004). Implementing Microsoft Excel Software for Rapfish: A Technique for the Rapid Appraisal of Fisheries Status. Canada: Fisheries Centre University of British Columbia.

Kay, R., \& Alder, Jaqueline. (1999). Coastal Planning and Management. New York: Routledge.

La Sara. (2014). Pengelolaan Wilayah Pesisir: Gagasan Memelihara Aset Wilayah Pesisir dan Solusi Pembangunan Bangsa. Bandung: Alfabeta.

Laras, B. K., Marimin, M., Nurjaya, I. W., \& Budiharso, S. (2011). Dimensi keberlanjutan pengelolaan Kota Tepian Pantai (Studi Kasus Kota Semarang). Forum Pascasarjana, 34(2), 89-105. Retrieved from https:/ $/$ www.google.co.id/url?sa=t\&rct=j\&q=\&esrc=s\&source=web\&cd=1\&cad=rja\&uact=8\&ved=0a hUKEwjBmr3IlIHYAhVHq48KHTC7Dx8QFggmMAA\&url=http\%3A\%2F\%2Fdownload.portalgaruda.or g\%2Farticle.php\%3Farticle\%3D86274\%26val\%3D245\%26title\%3DHandling\%2520Operation\%2520Sus tainability $\% 2520$ (Case $\% 2520$ Study\%3A\%2520Semarang\%2520Waterfront)\&usg=AOvVaw2wUwryrFM Jb6R9Y28npAgZ.

Lubis, J. (2011). Mewujudkan pembangunan Kota Pesisir di Indonesia yang berkelanjutan melalui penyediaan infrastruktur berbasis penataan ruang. In Buletin Tata Ruang BKPRN Edisi Juli-Agustus (Pembangunan). Jakarta: Badan Koordinasi Penataan Ruang Nasional.

Pitcher, T. J., \& Preikshot, D. (2001). RAPFISH: A rapid appraisal technique to evaluate the sustainability status of fisheries. Fisheries Research, 49(3), 255-270. doi: 10.1016/S0165-7836(00)00205-8.

Rizal, A. (2013). Disparitas pembangunan wilayah pesisir (Studi Kasus Kabupaten Tasikmalaya). Jurnal Akuatika, IV(2), 115-130. $\quad$ Retrieved from http://jurnal.unpad.ac.id/akuatika/article/download/3144/2405.

Santoso, L., Patandiana, M. V., \& Faiza, F. (2012). Identifikasi potensi wisata pantai di Kota Baubau. In Prosiding Group Teknik Arsitektur (Vol. 6, pp. 978-979). Makassar: Jurusan Teknik Arsitektur Fakultas Teknik Universitas Hasanuddin. from https://www.google.co.id/url?sa=t\&rct=j\&q=\&esrc=s\&source=web\&cd=1\&cad=rja\&uact=8\&ved=0a hUKEwjOnO7imIHYAhXLRo8KHXMnB_AQFggmMAA\&url=http\%3A\%2F\%2Fdownload.portalgaruda. 
org\%2Farticle.php\%3Farticle\%3D94528\%26val\%3D2170\&usg=AOvVaw15UQxdFO41hrIKr3LEse-T.

Sudarya, D., Sitorus, S. R. P., \& Firdaus, M. (2013). Analisis perkembangan ekonomi wilayah untuk arahan pembangunan kecamatan di wilayah pesisir Kabupaten Garut. Jurnal Ilmiah Geomatika, 19(2), 134-140. Retrieved from http://jurnal.big.go.id/index.php/GM/article/view/20.7.

Wibowo, G. D. H. (2009). Aspek hukum dan kelembagaan dalam peningkatan efisiensi dan efektifitas pengelolaan wilayah pesisir. Jurnal Hukum Ius Quia Iustum, 16(1), 127-144. doi: 10.20885/iustum.vol16.iss1.art8. 